\title{
ALÉM ATLÂNTICO: A PRÁTICA TRADUTÓRIA DE HERBERTO HELDER
}

\author{
Sabrina Sedlmayer* \\ Universidade Federal de Minas Gerais
}

\begin{abstract}
Resumo: A tradução, na obra do escritor Herberto Helder, opera uma sinuosa reescrita que visa a atualização de vozes de poetas que, em temporalidades distintas, culturas diversas, partilharam elementos acerca de um específico saber poético. A hipótese que se levanta é que a via a que recorre o poeta português para o estabelecimento do diálogo com textos outros não se restringe ao espaço de uma memória nacional ou de um imaginário imperialista e mítico português. Helder se detém, como tradutor, na poesia ameríndia - asteca, quíchua, Yuma, Sioux, Omaha, Navaja, na dos índios das montanhas rochosas, na dos peles-vermelhas - como também na dos esquimós, tártaros, japoneses, indonésios, árabes-andaluzes e mexicanos do ciclo nauatle. A sua prática tradutória parece recusar a noção de literatura como discurso historicamente demarcado no espaço e no tempo ao ignorar parte considerável da poesia moderna oriunda da civilização européia. Escolhe poetas e poemas não em termos utópicos de uma circunscrição de uma única língua portuguesa, mas vozes que heterodoxalmente mesclam lucidez com desvario.
\end{abstract}

Palavras-chave: Herberto Helder. Tradução. Atlântico. Nachleben.

\footnotetext{
* Formação em Psicologia, Universidade Federal de Minas Gerais. Mestrado em Literatura Brasileira, Universidade Federal de Minas Gerais. Doutorado em Literatura Comparada, Universidade Federal de Minas Gerais. Pós-Doutorado em Teoria da Literatura, Universidade Estadual de Campinas. Professora Adjunta da Faculdade de Letras da Universidade Federal de Minas Gerais. Belo Horizonte, Minas Gerais, Brasil. E-mail: sabrina.sedlmayer@gmail.com
} 


\title{
BEYOND ATLANTIC: THE TRANSLATION PRACTICE OF HERBERTO HELDER
}

\begin{abstract}
Translation, in the work of writer Herberto Helder, performs a winding rewriting aimed at reenacting the voices of poets who, in different times and cultures, shared elements of a specific poetic knowledge. In the present study, I consider the hypothesis that the ways explored by the Portuguese poet to set up a dialogue with other texts are not restricted to the realm of a national memory nor to any sort of Portuguese mythic-imperialistic imaginary. As a translator, Helder keeps his attention on the Amerindian poetry - from the Aztec, Quechua, Yuma, Sioux, Omaha, Navajo, and Rocky Mountain peoples - as well as on the Eskimo, Tartar, Japanese, Indonesian, Arabic-Andalusian and Mexican Nahuatl poetic traditions. His translation practice seems to refuse the notion of literature as a discourse historically delimited in time and space, once he ignores a considerable part of European civilization modern poetry, and does not choose poets and poems for their belonging to a utopic only Portuguese language, rather preferring voices that heterodoxically mix raving and lucidity.
\end{abstract}

Keywords: Herberto Helder. Translation. Atlantic. Nachleben.

Durante muito tempo o mar português foi analisado, de forma oscilante e às vezes intrincada, por três perspectivas hegemônicas: uma, baseada na ideia de acúmulo, de que o alargamento da riqueza material necessariamente se encontrava algures; outra, que respondia ao desejo de fuga e de errância devido a uma angústia territorial; e uma terceira, que sempre relevou a importância da disseminação da fé cristã pelo mundo, se sustentava numa espécie de vocação de povo eleito.

O fato é que a literatura tomou mais do que o lado sul e oeste do seu país como mote, tema, música e forma. Aprofundou a relação com o movimento oceânico e daí estabeleceu impasses. No paralelismo das barcarolas, na epopeia do peito ilustre lusitano, no deambular de Cesário, na ode masoquista de Campos, na maresia-poesia de Sophia, o mar sempre se apresenta como uma espécie de ritornello com os mais variados fins, nem sempre coincidentes com as leituras embasadas em argumentos materialistas, historicistas, míticos ou fenomenológicos. 
Duas recentes edições críticas retornam vigorosamente esse assunto e com curiosas inflexões interpretativas propõem uma análise capaz de deslocar as posições citadas anteriormente ao lançarem questões que ampliam a discussão sobre a tarefa da tradução, a saber: Poetas do Atlântico, de Irene Ramalho Santos, e Exceção Atlântica, de Roberto Vecchi.

Apesar de princípios teóricos muito diferentes, ambas as obras ressituam o Atlântico. Para Ramalho Santos, urge desvencilhar a ideia de literatura nacional em termos autotélicos e ampliar a compreensão rumo a uma hetero-referencialidade, uma vez que o modernismo anglo-americano, afinado com a produção de Fernando Pessoa, "obriga a olhar a tradição poética ocidental como uma tradição de cruzamentos atlânticos e referências mútuas, assentes em fluxos e complexos actos de porosidade" (SANTOS, 2007, p. 19). O objetivo da ensaísta é promover o diálogo de Fernando Pessoa com a tradição poética anglo-americana (gesto já ensaiado, é bom lembrar, por Jorge de Sena nos anos 1970 e atualizado por George Monteiro, na década de 80 do século passado) e também reavaliar as implicações ideológicas da poesia modernista, ao ler Mensagem, por exemplo, não como hino à nacionalidade lusitana, mas como uma espécie de reinvenção de um sistema mundial em que a nação seria parte, mas não caberia à poesia a justificativa de pertença. Pessoa seria um "mestre heteronímico de alteridade passa-fronteiras, de espelho estilhaçado do paradigma anterior" (SANTOS, 2007, p. 20). E, mais do que isso, defensor de que os poemas, antes da aliança com línguas, nações ou impérios, são poemas escritos num sistema mundial. A tradição só faria sentido, então, se estudada à luz de um paradigma analítico pós-nacionalista, em um processo de extroversão, de busca de identificações que só existem essencialmente como procura e deriva. Daí o objetivo do livro: realojar Fernando Pessoa na tradição heterogênea de poetas do Atlântico.

Se é possível observarmos eco de algo que Jorge Luis Borges já anunciava, em 1953, acerca dos pseudoproblemas do escritor e a tradição, ${ }^{1}$ é interessante reter aqui a observação de que a poética pessoana é complexa e contraditória o bastante por tentar, por um 
lado, romper com o sonho imperialista português e, por outro, almejar cumprir poeticamente a dominação heroica de que o país não pode mais sustentar política e economicamente.

Retenho, neste momento, a primeira indagação deste meu trabalho: até que ponto a ensaísta portuguesa estaria afinada com a hipótese "espiritual" construída por Harold Bloom (2007), no prefácio de seu livro, de que a poesia atlântica buscaria uma Atlântida perdida "como uma ficção credível" e de que, independente dos contextos, toda poesia atlântica é visionária? ${ }^{2}$ Em que medida a sua leitura corroboraria, dessa forma, com certa mitificação de Pessoa em "seus múltiplos eus" e o labiríntico "mistério de sentido"?

Já a obra de Roberto Vecchi, abrigada sob a rubrica dos Post-Conflict Cultures, aposta na possibilidade de que a guerra colonial tornou-se um dos modos mais fecundos de refletir sobre Portugal, e que a palavra "excepção" é potente o bastante para se constituir como um conceito crucial a fim de se efetuar uma genealogia calcada mais na rememoração do que na historiografia das continuidades. Retomando a provocação anunciada por Eduardo Lourenço de que o país poderia ser descrito como uma ilha saudade, uma "insólita excepção portuguesa", o ensaísta italiano analisa a literatura produzida na guerra colonial, justamente no momento histórico em que o império português se despedaça, e indaga se esse longo episódio seria mesmo uma guerra fantasma ou a "continuação de uma permanência histórica de séculos de colonialismo português, ele próprio marcado pelo traço real ou imaginado - da excepção, a “excepção atlântica'” (VECCHI, 2010, p. 15).

Um dos principais eixos interpretativos utilizado por Vecchi para efetuar uma genealogia da exceção é calcado no pensamento de Giorgio Agamben, que recoloca, de forma elaborada e ampliada, tanto em termos teóricos quanto políticos, a célebre tese VIII de Walter Benjamin, de "o estado de exceção no qual vivemos é a regra". Como se sabe, essa tese possui ressonâncias pontuais com o livro de Carl Schmitt, Politische Theologie, de 1921, que se debruça sobre as particularidades da identificação entre a soberania e o estado de exceção. 
Curioso lembrar que a palavra "exceção", para Agamben, possui um lugar simétrico à palavra "exemplo", sendo que a primeira é definida como exclusão inclusiva, e a segunda, como inclusão exclusiva:

\begin{abstract}
Nem particular, nem universal, o exemplo é um objeto singular que, digamos assim, se dá a ver como tal, mostra a sua singularidade. Daí a pregnância do termo que em grego exprime o exemplo: para-deigma, o que se mostra ao lado (como no alemão Bei-spiel, o que joga ao lado). Porque o lugar próprio do exemplo é sempre ao lado de si próprio, no espaço vazio em que se desenrola a sua vida inqualificável e inesquecível. (AGAMBEN, 1993, p.16)
\end{abstract}

Em movimento, sempre dinâmico, exemplo e exceção funcionam como polos oscilatórios, daí entender a narrativa de um país excepcional que fora, com o tempo, transformado na exceção $d a$ e $n a$ história.

Sem, no entanto, me deter nas consequências do aporte teórico benjaminiano/agambeniano, gostaria de sintetizar quais ondulações críticas o conceito de "exceção" oferece a Vecchi para interrogar algumas aporias históricas, principalmente acerca do colonialismo precoce e da "suave" guerra colonial portuguesa. A trajetória argumentativa do livro pode ser colocada da seguinte forma: um povo que acredita ser possuidor de uma história de exceção vive um estado de exceção permanente, sem interrupção. E esse viver utópico não é nada ingênuo.

Ao tentar, então, no emaranhado de mitos fundadores da história nacional, tomar a literatura da guerra como uma anamnese e cotejar o tenso diálogo da memória como esquecimento, Vecchi constata como a exceção serviu para mascarar os discursos luso-tropicalistas e a crioulidade.

Se a modernidade portuguesa, retorcida e dissonante, possui uma relação tensa com o esquecimento, cabe à literatura atritar, 
dar indícios, formular paradoxos e lembrar que a memória exige tradução.

Tido como uma das vozes mais intensas, talentosas e complexas da literatura portuguesa a partir de 1950, Herberto Helder é um tradutor silencioso que vem, há anos, construindo uma sólida obra que obstinadamente dialoga com as noções de memória e de tradução. Henri Michaux (1967), talvez o mais próximo dos seus interlocutores, oferece o método: "Aprender: traduzir. E tudo é tradução, em todos os níveis, em todas as direções”.

Tentar se aproximar, um pouco, da trajetória desse tradutor que "muda poemas para o português" e se afasta audaciosamente da tradição atlântica (camoniana, pessoana, poderíamos acrescentar) em busca uma linhagem "afro-carnívora", é o que pretendo desenvolver na segunda parte deste ensaio.

\section{Ouves os gritos dos mortos?}

No pequeno prefácio da antologia Edoi lelia doura, Herberto Helder conta duas histórias: uma japonesa e outra afro-carnívora. A segunda, para um leitor familiarizado com a sua escrita, é capaz de dizer quase tudo acerca da sua máquina lírica. Trata-se de uma narrativa sobre uma tribo que sepultava os mortos no côncavo de grandes árvores. "Baobás" era o nome das árvores e também do povo. Alquimia, devir, transmutação: todos esses termos são passíveis de serem dados ao processo metamórfico entre a carne humana e o esquema orgânico da matéria. Explica o antologista: "pelo nome tirado de si e posto na alquimia, a tribo investia-se nas transmutações gerais: a morte levava o nome, e o nome, activo e tangível, crescia na terra" (HELDER, 1985, p. 7).

Se essa história serve para ilustrar o método criativo do poeta e a sinuosa reescrita que visa a atualização de vozes de escritores que, em temporalidades distintas, culturas diversas, partilharam elementos acerca de um específico saber poético, é também pertinente para apontar a genealogia de escritores que formam a árvore 
carnívora de Herberto Helder. A via a que recorre o poeta para o estabelecimento do diálogo com textos outros - que denomina "vozes comunicantes" -, que nos remete imediatamente aos "vasos comunicantes", de André Breton (1955), não se restringe à criação de uma linhagem de uma memória nacional ou de um imaginário mítico português. Helder se detém, como tradutor, na poesia ameríndia - asteca, quíchua, yuma, sioux, omaha, navaja, na dos índios das montanhas rochosas, na dos peles-vermelhas - e também na dos esquimós, tártaros, japoneses, indonésios, árabes-andaluzes e mexicanos do ciclo nauatle.

O que aparentemente pode parecer um cânone bizarro é e não é, conforme alerta Manuel Gusmão. É e não é “a manifestação de uma preferência ou de "afinidades electivas", que é ao mesmo tempo um retrato de família ou a invenção de uma linhagem; em suma, a cartografia de um sistema de vozes múltiplas que se afirma comunicarem entre si no que é um sistema de encontros (GUSMÃO, 2010, p. 341).

Pouco potentes, o conceito de intertextualidade cultural ou de aculturamento parecem não dizer muito para o gesto helderiano de trazer para a cena literária portuguesa vozes completamente silenciosas à cultura do seu país de origem. Maria Helena Buescu denomina de "onívora" essa poética que se imagina como um lugar espesso capaz de incorporar antropofagicamente muitas vozes e sobretudo aumentar a consciência de como a tradição é construída não como fusão, mas como estranhamento (BUESCU, 2009, p. 50). Há um respeito pela alteridade, mas os textos são integrados e compostos via colisão, sem preocupação em identificar a origem, data, local ou qualquer índice da condição de produção. O que parece mover Helder, completa a crítica, é mais a determinação de "dar a ver" as zonas obscuras, esquecidas pelo ocidente.

$\mathrm{Na}$ antologia citada (1985), poetas como Gomes Leal, Ângelo de Lima e António Gancho, tidos como "loucos" e "miseráveis", são recuperados junto aos surrealistas Cesariny, António Maria Lisboa, Nathália Correia e António José Forte. Nesse livro, alicerçado segundo a "posse dos encontros" (HELDER, 1985, p. 8), 
o antologista seleciona 18 poetas portugueses que, em sua visão, possuem uma inspiração em comum, "uma comum arte do fogo e da noite, o mesmo patrocínio constelar" (HELDER, 1985, p. 8). Como antologista, Helder escolhe a ênfase, a loucura, o êxtase, a inocência, o primitivo, da mesma maneira que escolhe poetas e poemas para o exercício tradutório. E a antologia responde, obliquamente, à reescrita de Húmus. "É preciso criar os mortos", atualiza Helder a voz do genial precursor Raul Brandão. A religiosidade gótica do romantismo alemão refeito lado a lado pela leitura de Brandão de Poe, Baudelaire, Dostoievski, Hoffmann, Freud, Nietzsche, tudo é metamorfoseado por Helder, modificado no presente.

$\mathrm{O}$ interesse pelas tradições arcaicas responde, em parte, a sua prática tradutória como busca de uma não-tradição. Mas a coerente recusa da noção de literatura como discurso historicamente demarcado no espaço e no tempo, a não absorção de parte considerável da poesia moderna oriunda da civilização europeia, e a escolha (não em termos utópicos de uma circunscrição de uma única língua portuguesa) de vozes que, heterodoxalmente, mesclam lucidez com desvario, numa relação de infinitude e estranheza, engendram a obra de Helder à tradição romântica alemã. De lá, uma ciência noturna, uma infinita estranheza e o apego à noção de sagrado. Do Surrealismo, a intensidade da procura por metáforas primitivas, infantis, vagas, loucas.

Parte considerável da crítica helderiana já salientou a dimensão trans-histórica, não periodológica do elenco de poetas traduzidos selecionados por uma espécie de escolha ético-poética: Blake, Artaud, Michaud, Hermann Hesse e Lawrence são traduzidos lado a lado aos poemas do Velho Testamento e do Egito Antigo. Em todos os seus cinco livros de tradução, a saber, $O$ bebedor noturno, Magias, Ouolof, Poemas ameríndios e Doze nós numa cor$d a$, acentua-se a predileção pela escolha de culturas que sofreram abusivamente colonização e cujos poemas são, no presente, uma espécie de Spuren (resto, rastro, vestígio), uma presença de uma ausência e ausência de presença. O gesto da tradução atualizaria, assim, a expressão simbólica quase extinta. 
Nesse sentido, o método de escolha de tradução de Helder possui curiosas afinidades com o de Aby Warburg e a sua ciência sem nome. Na recusa ao método estilístico-formal, no salto das falsas divisões, periodizações e hierarquias, na severa manutenção de uma "honesta repugnância" frente a história entendida como continuidade, a obsessão pelo mito, o entrelaçamento entre palavra e imagem, o logos da techné oposto à dimensão mitopoética, o valor desmesmesurado à técnica da montagem, mas, fundamentalmente, a crença de que existe uma complexa e densa memória de imagens que sobrevivem através de determinadas leis de recepção e transmissão, une as experiências de pathos de ambos. Na conclusão de um instigante ensaio dedicado à Warburg, Giorgio Agamben aponta que na busca heterodoxa de Walter Benjamin sobre a imagem dialética poderíamos reconhecer uma deriva fecunda do legado warburguiano. Ora, a imagem dialética, essa recordação involuntária da humanidade, essa imagem onde aloja o tempo, temporalidade em saltos, acredita na rememoração. E poderíamos completar: o que faz Herberto Helder quando toma para si a necessidade de se criar os mortos?

Essas considerações, que merecem um comentário mais extenso e rigoroso, são trazidas a essa discussão apenas para sublinhar como o que pode ser a linha de força da prática helderiana: a rememoração ou da Nachleben, a relação entre transmissão, de um renascimento que parece ser o ponto crucial da tarefa de tradutor tomada por Helder. Na conhecida conferência "A imagem crítica," de Didi-Huberman (1992), há também a observação acerca do resto, da "sublime violência do verdadeiro" que existe em toda filosofia do vestígio. Há um certo anacronismo, completa o teórico francês citando P. Fédida, "passado anacrônico e presente reminiscente".

Ao ir contra o que seja moderno, racionalista, investigativo e utilitarista, Helder, como tradutor, considera "o espírito enfático da magia" e vai longe, "aos recônditos do tempo" (HELDER, 1983 , p. 11). Maias e astecas, ou guaranis e koguis, além de se relacionarem de forma ritualística com a linguagem, possuem uma noção de inocência cara ao poeta português. Numa curiosa auto- 
entrevista, desvencilhando-se da influência do Surrealismo (amplamente associado à sua poesia), sublinha:

\begin{abstract}
Sente-se um tremor secreto na palavra, desde a origem, desde as invocações e as imprecações dos feiticeiros, dos xamãs, dos hierofantes; esse tremor desaparece de súbito e um dia reaparece; sempre assim ao longo da história da palavra; deve-se ao surrealismo, numa época sem tremor, ter dito que ele existia; alguns surrealistas, não muitos, nunca são muitos, tinham os pés colocados sobre a linha sísmica que atravessa a terra, e vê-se que tremiam dos pés à cabeça, a sua palavra tremia na boca furiosamente enfática.
\end{abstract} (HELDER, 2001, p. 11)

Se por um lado podemos identificar uma linhagem messiânica, sucessora dos românticos (ou órfica ou xamânica, como preferem outros, fiel a essa noção de chama que atravessa os tempos e é recebida e transmitida por poucos), há uma outra observação importante a ser feita a título de conclusão: ao recusar o termo tradução (nunca tê-lo empregado), e atualmente adotar "poemas mudados para o português" e ter eliminado "versão", Helder constrói uma coerente estratégia além-atlântica, rumo a uma concepção que renuncia as oposições binárias típicas de qualquer movimento de recuperação de significados de uma língua para a outra ou para qualquer angústia diante da tradição.

As três precauções negativas, como aponta Derrida, leitor de Benjamin, estão presentes nesse exercício: não ater à recepção, nem à comunicação, nem à representação (DERRIDA, 2002, p.35) ${ }^{3}$. É o que se percebe no conhecido prefácio, escrito em 1968 (e atualmente excluido de todas edições):

Já me aconteceu imaginar a vida acrobática e centrífuga de um poliglota. Suponho o seu dia a dia animado por um ininterrupto movimento de deslocações, transmutações, permutas e exaltantes caçadas de equivalências, sob o signo 
da afinidade. Vive das significações suspensas, da fascinação dos sons que convergem e divergem - e há nele, decerto, um desespero surdo, pois que na desunião dos idiomas busca a unidade improvável. Multiplicando as operações de propiciação da unidade, ele caminha irradiantemente para a dispersão. Descentraliza-se. Existe em estado de Babel. O seu pensamento, partindo do hebraico, dá um salto quase místico no latim e cai de cabeça para baixo no grego antigo. É um aventureiro completamente perdido, o meu poliglota cheio de malícias linguísticas. Faz disparates destes: verte de nauatle para esquimó, emocionando-se em banto e pensando em chinês, um texto que o interessou por qualquer ressonância árabe. Também pega na palavra «cravo» e tradu-la para quinze línguas. O cravo é cada vez menos cravo. É uma colorida e abstracta proliferação sonora. Então, ele junta ao cravo aramaico o adjectivo turco «branco». Encontra-se, neste momento, em plena vertigem paranóica-idiomática. É um perfeito irrealista - e eu amoo, à distância. (HELDER, 1995, p.71)

Ao afirmar que desconhece línguas, que é movido por um prazer deambulatório, amor projetivo, e as mudanças dos poemas serem apenas "explosões velozmente laboriosas", Helder, além de apontar afinidades entre línguas, constrói sobrevida. Nesse país que acreditou se alojar "onde a terra se acaba e o mar começa", o poeta não parece desejoso de recuperar algo que se perdeu, mas de, reiteradamente, propor mudança, intervenção, ao abrir vias, viagens não teleológicas, para o ontem ser diferente no hoje. 


\section{Notas}

1. Refiro-me à palestra proferida por Borges, "O escritor argentino e a tradição", em que, após salientar alguns pontos imprescindíveis para a análise do problema, considera-o um simulacro, apenas uma aparência. Finaliza concluindo: "Creio que a nossa tradição é toda cultura ocidental, e creio que temos direito a essa tradição, maior que o que podem ter habitantes de qualquer outra nação ocidental" (BORGES, 1998).

2. Prefácio de Poetas do Atlântico (2007, p. 11-12).

3. Completa Derrida: "o sagrado é traduzível (ubersetzbar) e intraduzível. Existe apenas letra, e é a verdade da linguagem pura, a verdade como linguagem pura" (DERRIDA, 2002, p.71). O sagrado surge assim, não como limite da traduzibilidade, mas um pas-de-sens, de algo que não possui sentido fora da sua literalidade.

\section{Referências}

AGAMBEN, Giorgio. A comunidade que vem. Tradução António Guerreiro. Lisboa: Presença, 1993.

. La puissance de la pensée: Essais et conférences. Paris: Bibliotèque Rivages, 2006.

BRETON, André. Les vases Communicantes. Paris: Gallimard, 1955

BLOOM, Harold. Prefácio. In: SANTOS, Irene Ramalho. Poetas do Atlântico. Fernando Pessoa e o modernismo anglo-americano. Belo Horizonte: Editora UFMG, 2007. 
BUESCU, Maria Helena. Uma ideia de poesia omnívora. Diacrítica, Minho, n. 23-3, 2009.

DERRIDA, Jacques. Torres de Babel. Tradução Junia Barreto. Belo Horizonte: Editora UFMG, 2002.

DIDI-HUBERMAN, Georges. Ce que nous voyons, ce qui nous regarde. Paris: Editions de Minuit, 1992.

GUSMÃO, Manuel. Tatuagem \& palimpsesto da poesia em alguns poetas e poemas. Lisboa: Assírio \& Alvim, 2010.

HELDER, Herberto. O bebedor noturno: Poemas mudados para o português. Lisboa: Assírio \& Alvim, 2010.

HELDER, Herberto. "Herberto Helder: entrevista". In: Inimigo rumor. Número 11. Rio de Janeiro: 7 Letras \& Cotovia, 2 semestre de 2001.

(Org.). Edoi Lelia Doura: antologia das vozes comunicantes da poesia moderna portuguesa. Lisboa: Assírio \& Alvim, 1985.

. Photomaton \& Vox. Lisboa: Assírio \& Alvim, 1995.

. Nota inútil (prefácio). In: FORTE, António José. Uma faca nos dentes. Lisboa: \& ETC, 1983.

MICHAUX, Henri. Ailleurs. Paris: Gallimard, 1967

VECCHI, Roberto. Excepção Atlântica: Pensar a Literatura de Guerra Colonial. Lisboa: Edições Afrontamento, 2010.

SANTOS, Irene Ramalho. Poetas do Atlântico: Fernando Pessoa e o modernismo anglo-americano. Prefácio Harold Bloom. Belo Horizonte: Editora UFMG, 2007. 


\section{Bibliografia consultada}

. Doze nós numa corda: Poemas mudados para o português. Lisboa: Assírio \& Alvim, 1997.

Poemas Ameríndios: Poemas mudados para o português. Lisboa: Assírio \& Alvim, 1997.

. Poesia toda. Lisboa: Assírio\&Alvim, 1997.

Recebido em: 12/02/2014

Aceito em: 23/05/2014 